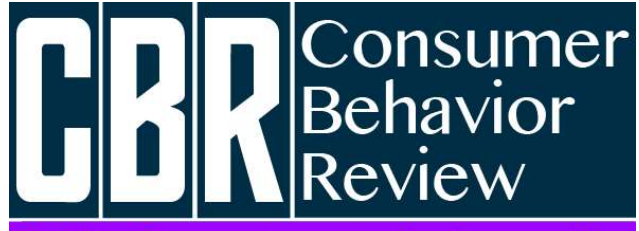

Revista Comportamento do Consumidor
Guerra, C. M., \& Dias, V. V. (2021). Marketing Sensorial e Consumidores com Deficiência: Uma análise a respeito da lembrança de marca. Consumer Behavior Review, 5(1), 140-157.
ISSN: 2526-7884

Editor: Prof. Dr. Marconi Freitas da Costa

E-mail:cbr@ufpe.br
Avaliação: Double blind review

Recebido: 8 de Junho, 2020

Aceito: 15 de Dezembro, 2020

\title{
MARKETING SENSORIAL E CONSUMIDORES COM DEFICIÊNCIA: UMA ANÁLISE A RESPEITO DA LEMBRANÇA DE MARCA
}

\author{
Sensorial Marketing and Consumers with Disabilities: An analysis regarding brand
} memory

\author{
Cristiane Medeiros Guerra ${ }^{1}$ \\ ORCID: http://orcid.org/0000-0002-1136-8180 \\ E-mail: crismedeirosguera@gmail.com \\ Valéria da Veiga Dias ${ }^{1}$ \\ ORCID: http://orcid.org/0000-0001-8962-1134 \\ E-mail: valeria-adm@hotmail.com \\ ${ }^{1}$ Universidade Franciscana, Santa Maria, Brasil
}

\begin{abstract}
Resumo
0 uso do Marketing sensorial vem se disseminando pela capacidade de criar experiências marcantes aos consumidores, que com o estímulo adequado, reagem ou criam memórias a respeito da marca. No entanto, nem todos os consumidores podem receber informações ou estímulos por meio de todos os sentidos, o que, em muitos casos pode significar alienação e falta de interação com as marcas. 0 objetivo deste trabalho foi analisar como estratégias de marketing sensorial são percebidas por consumidores com deficiência auditiva e visual. A metodologia foi classificada como descritiva e exploratória, com abordagem qualitativa na coleta e análise de dados. Realizou-se uma pesquisa de campo e a
\end{abstract}

\begin{abstract}
The use of sensory marketing has been spreading due to the ability to create remarkable experiences for consumers, who with the appropriate stimulus, react or create memories about the brand. However, not all consumers can receive information or encouragement through all the senses, which in many cases can mean alienation and lack of interaction with brands. The objective of this work was to analyze how sensory marketing strategies are perceived by consumers with hearing and visual impairments. The methodology was classified as descriptive and exploratory, with a qualitative approach in the collection and analysis of data. Field research and semi-structured interviews
\end{abstract}


entrevistas semiestruturadas. A análise dos dados se deu por análise de conteúdo. Pode-se observar que os deficientes sensoriais são limitados nas suas escolhas, por falta de acessibilidade, principalmente quando a comunicação da marca não consegue atingir completamente os públicos, já que um aspecto sensorial diferente poderia ser usado para pessoas que possuem alguma limitação. Por mais que o marketing sensorial aproxima-se estrategicamente das pessoas, sozinho não consegue comunicar-se plenamente com este público. Os deficientes sensoriais conseguem realizar compras, mas poucos desenvolvem preferências pessoais, e quando possuem, baseaim-se em influencia de familiares, amigos e conhecidos.

Palavras-chave: Consumidor, Decisão de compra, Significados, Percepção. were carried out. Data analysis was done through content analysis. It can be seen that the sensory impaired are limited in their choices, due to lack of acces

sibility, especially when the brand communication is unable to reach the public completely, since a different sensory aspect could be used for people who have some limitations. As much as sensory marketing strategically approaches people, it alone cannot communicate fully with this audience. The sensory impaired are able to make purchases, but few develop personal preferences, and when they do, they are based on the influence of family, friends and acquaintances.

Keywords: Consumer, Purchase decision, Meanings, Perception.

This work is licensed under a Creative Commons Attribution 4.0 International License.

\section{INTRODUÇÃO}

0 marketing existe na vida dos consumidores desde antes do que se imagina. Partindo de uma troca de produtos entre algumas pessoas no passado, a um clique na internet entre milhares de consumidores. Essas transformações possibilitaram abranger um número maior de pessoas sejam elas clientes ou possíveis consumidores. Para Minuzzi e Larentis (2014), embora o marketing tenha mudado ao longo do tempo, pode-se afirmar que sua essência está em entender o mercado e atendê-lo, o que pode continuar servindo de guia, através das várias outras mudanças. Para alcançar as mudanças no próprio contexto do mercado, o marketing se revestiu de diferentes estratégias, que auxiliam no alcance de resultados.

O marketing tradicional visava as necessidades do cliente, como por exemplo a comunicação antes era sempre visual, o foco era vender o produto e desenvolver o produto. Conforme o tempo passa essas necessidades se alteram nasce o surgimento de novas estratégias de marketing. No entanto, $o$ marketing dos cinco sentidos está cada vez mais presente nas estratégias das empresas, que buscam ampliar a relação emocional com potenciais clientes e proporcionar experiências no momento da compra. Além disso, ao entregar valor superior aos consumidores nas compras, o marketing sensorial se baseia na análise da percepção dos consumidores em relação a determinadas marcas e produtos com base em cada um de seus sentidos (sensoriais, emocionais, cognitivos e comportamentais) (Jiménez \& Elías, 2018).

Como uma faceta contemporânea, o marketing sensorial apresenta-se como uma possibilidade diferente de entregar valor e satisfazer a necessidade dos clientes por meio de ações que buscam explorar os sentidos através de experiências (Lindstrom, 2012). Para Soares (2013), a exploração dos sentidos pelo marketing sensorial contribui para influenciar as decisões do consumidor, promovendo por meio dos cinco sentidos, experiências sensoriais conscientes e inconscientes. 0 marketing sensorial pode explorar os cinco sentidos juntos ou até mesmo separados. Cada sentido humano origina diferentes sensações e diferentes experiências sensoriais. Como seres humanos, somos de longe mais receptivos quando operamos nas cinco faixas, "nossos cinco sentidos" (Lindstrom, 2012, p.14).

Dentro de uma perspectiva de uma abordagem democrática, as ações do marketing sensorial podem trazer benefícios à comunicação das marcas, produtos e serviços, à diferentes públicos, inclusive àqueles que tenham alguma limitação em compartilhar da comunicação mais tradicional, a qual 
geralmente explora recursos visuais e/ou auditivos (Lindstrom, 2012). 0 marketing sensorial por meio de suas ações permite dialogar com os públicos com as mais diversas necessidades, inclusive com pessoas que tenham algum tipo de deficiência. A partir do momento que ele propõe ações que explorem os demais sentidos, não limita o público alvo, a ação ou estratégia para comunicar-se. Deste modo, pode atingir esse público, à medida que se propõe a trabalhar os sentidos bem como produzir impacto através de uma abordagem que se aproxima das pessoas com deficiência.

Conforme estabelece o art. $2^{\circ}$ da nova lei de Inclusão da Pessoa com Deficiência:

considera-se pessoa com deficiência aquela que tem impedimento de longo prazo de natureza física, mental, intelectual ou sensorial, o qual, em interação com uma ou mais barreiras, pode obstruir sua participação plena e efetiva na sociedade em igualdade de condições com as demais pessoas (Decreto Lei 끈 13.146/2015, 2015 p.1219)

O novo conceito excede a ideia de impedimento como sinônimo de deficiência, reconhecendo na contenção de participação o fenômeno determinante para a identificação da desigualdade pela deficiência (Diniz, 2009). Neste sentido, este estudo focou-se em entender, não apenas as percepções dos consumidores, mas também avaliar a capacidade das empresas para explorar estratégias baseadas em quatro sentidos, que não sejam aqueles da qual o consumidor não tem acesso, consideradno a possibilidade de gerar lembrança e identificação com as marcas, experiências sensórias e dialógo com o cliente. Através das experiências e estratégias como uso de músicas, aromas, vitrines luminosas e degustações algumas empresas tem conseguido, com criatividade atingir diversos públicos. Como consequência das experiencias as pessoas acabam tendo suas preferências e costumam ser fiel as marcas. Partindo dessa premissa portanto, esta pesquisa busca responder a seguinte questão: Como as estratégias de marketing sensorial e comunicação da marca são percebidas por consumidores com deficiência?

O objetivo desta pesquisa consiste em analisar como as estratégias de marketing sensorial e comunicação da marca são percebidas por consumidores com deficiência. No que se refere as estratégias de marketing sensorial o propósito é investigar que tipo de relação as empresas estabelecem com este cliente e se conseguem estabelecer uma relação a ponto de criar uma lembrança, uma identificação ou preferência. Isso porque tais percepções se refletirão em opiniões, atitudes, ações de compra, além de sinalizarem necessidades de adequação estratégica, já que a falta de relacionamento e diálogo também é um indicador importante para marcas.

Percepções positivas são as primeiras possibilidades de estabelecer uma "conversa" com o consumidor e despertar interesse por uma marca, que se desenvolvida de forma adequada pode resultar em fidelização e promoção da marca por parte do próprio cliente. Quando a marca consegue perceber as reais necessidades do cliente, pode se conectar e assim atender não apenas um cliente, mas grupos que podem necessitar de representatividade perante o mercado.

Assim, esta pesquisa justifica-se a partir de uma investigação capaz de trazer reflexões acerca da necessidade de ampliação do escopo de estratégias de Marketing, considerando a possibilidade de que alguns grupos de consumidores possam não ser alcançados ou atendidos por meio das estratégias de comunicação atuais. Implicando na necessidade de se pensar no marketing em termos mais globais para alavancar esses segmentos.

Estudos diverso abordam a temática no que tange á deficiência de mobilidade e acesso, principalmente para o público idoso ou turistas (Miethlich \& Oldenburg, 2019; Benjamin, Bottone \& Lee, 2020), mas quando se fala em acesso a informação oriundo da fontes sensoriais ou comunicação não visual, existe uma carência de estudos e preocupação.

Nota-se esta necessidade de redesenho e planejamento para o futuro em estudos que exploram temática semelhante, como Scaraboto e Fischer (2013) que abordam o tema a partir da ótica de consumidores marginalizados, nomeado como fatshionista, caracterizados como aqueles que não se encaixam nos padrões da moda tradicional, no entanto, estes grupos de consumidores podem alavancar uma nova lógica, uma busca dentro de um mercado particular e a criação de uma nova identidade coletiva. 
A realidade das campanhas de marketing, é que dificilmente são pensadas e projetadas para pessoas, que fogem do "padrão comum", além de que, muitas vezes a questão sensorial é desconsiderada nas estratégias de comunicação, principalmente quando a questão envolve se conectar com possíveis consumidores com alguma deficiência sensorial. 0 fato é que as pessoas com alguma deficiência atualmente formam um amplo mercado consumidor. Ainda que sejam mais de 45 milhões de pessoas, poucas vezes se observam estratégias específicas voltadas para elas. A deficiência visual está presente em 3,4\% da população brasileira e a deficiência auditiva em 1,1\%. Ao considerarmos também as pessoas com alguma dificuldade, $18,8 \%$ da população apresentou dificuldade para enxergar; e 5,1\% possuía dificuldade para ouvir, essas dificuldades são consideradas deficiência, dados segundo o Instituto Brasileiro de Geografia e Estatística (IBGE, 2010).

Dessa forma, reitera-se a importância de se pensar em ações para esse público, que também é consumidor, buscando entregar valor e fidelizar essas pessoas. 0 marketing faz a ligação entre empresa e sociedade, o canal que vai incorporar dentro das estratégias comunicativas contribuindo para sua conformação enquanto público ativo de consumo.

\section{MARKETING E MARKETING SENSORIAL}

O Marketing foi elaborado para amplificar o mercado de vendas, de produtos e serviços. Envolve criação, adaptação de produtos e serviços, entrega de melhor valor/produto para os clientes, cria um ambiente propício para a inovação e criatividade, com desenvolvimento de novas potencialidades e na formação de novos públicos (Bragança Zaccaria \& Pitomba, 2016). O marketing tem evoluído constantemente, compelindo os empresários e profissionais de marketing a reciclarem-se regularmente. Buscando inovações nas tendências e adaptando sua empresa as novas modalidades que despontam com o movimento dos consumidores no mercado.

Kotler, Kartajaya e Setiawan (2017), classificaram o Marketing em quatro fases ou eras, 1.0 a da produção, 2.0 focado no consumidor ,3.0 com evidência o ser humano com base no mercado e 4.0 um aprofundamento e ampliação do marketing centrado no ser humano. Constatou-se a necessidade de afunilar ainda mais os laços, onde os consumidores passaram a serem vistos como seres humanos plenos, com mente, coração e espírito. Este relacionamento, segundo Rez (2018), é baseado em valores em comum, por isso as marcas começaram a investir em posicionamentos mais humanizados, criação de vínculos emocionais e atribuição de significado emocional aos seus produtos e serviços como o marketing sensorial.

O marketing sensorial surgiu na área da psicologia/comportamento do consumidor e da teoria de experiência do cliente. Apresentado por Holbrook e Hirschman (1982) em que afirma que experiências são fenomenológicas e resultam da percepção/interpretação do indivíduo em relação a situação vivida. Acevedo e Fairbanks (2018) apresentam o marketing sensorial como uma experiência de compra memorável, fixando a marca na mente de seus consumidores.

Segundo Lindstrom (2012, p.10) "psicólogos comportamentais estimam que cerca de $80 \%$ das impressões que formamos quando nos comunicamos com outras pessoas não são verbais, o que significa dizer que são sensoriais". Utilizando dessa sensorialidade a necessidade de se realizar uma comunicação mais eficiente e completa, utilizando os cinco sentidos biológicos dos consumidores. A percepção dos sentidos humano se dá como aprendemos, paladar $1 \%$, tato $1,5 \%$, olfato $3,5 \%$, audição $11 \%$ e visão $83 \%$, (Blessa, 2011). 0 autor Lindstrom (2012) reconhece ao afirmar que pouquíssimas campanhas publicitárias se atentam em usar mais do que a visão e a audição para divulgar suas mensagens. 0 Quadro 01 a seguir representa os cinco sentidos que são explorados pelo marketing sensorial.

\begin{tabular}{|l|l|}
\hline Visão & $\begin{array}{l}\text { A visão é o primeiro sentido que impulsiona o cérebro ao encontro do produto. Um produto } \\
\text { com uma aparência atraente tende a capturar com facilidade o interesse do consumidor e a } \\
\text { prender a sua atenção por mais tempo (Ditoiu \& Caruntu, 2013). }\end{array}$ \\
\hline Audição & $\begin{array}{l}\text { Os principais elementos auditivos sensoriais são: som, música, tom, ritmo e melodia. Ouvir é } \\
\text { quando o receptor, no caso o consumidor, apenas recebe informações, mas escutar é quando } \\
\text { o consumidor assimila e filtra esse estímulo gerando então uma reação (Lindstrom, 2012). }\end{array}$ \\
\hline Tato & $\begin{array}{l}\text { Para Parente (2010) o tato é o meio através do qual consente ao consumidor perceber as } \\
\text { características físicas do produto. Esse contato físico produz sensação antecipada de posse do }\end{array}$ \\
\hline
\end{tabular}




\begin{tabular}{|l|l|}
\hline & $\begin{array}{l}\text { produto e influencia diretamente a decisão de compra, sendo esta indispensável para esse } \\
\text { processo. }\end{array}$ \\
\hline Paladar & $\begin{array}{l}\text { O paladar, requer mais cautela quando aplicado como estratégia de marketing sensorial, pois } \\
\text { é mais complicado agradar os paladares tão variados das pessoas, mas não deixa de ser um } \\
\text { potencial sentido a ser usado. }\end{array}$ \\
\hline Olfato & $\begin{array}{l}\text { O olfato remete as lembranças, traz o passado para o presente. Poucas marcas criam aromas } \\
\text { distintos, afirma Lindstrom, (2012). }\end{array}$ \\
\hline
\end{tabular}

Fonte: Elaborado pelas autoras

Quadro 01. Os cinco sentidos que são explorados pelo marketing sensorial

Krishna (2011) define marketing sensorial como 'marketing que envolve a mente dos consumidores e afeta sua percepção, julgamento e comportamento', quando se trata de compreender conceitos como percepções e sensações. Além disso, sugere-se que os cinco sentidos impactam as atitudes, aprendizado e comportamento do consumidor. As empresas além de criar valor para seus clientes através dos cinco sentidos necessita comunicar-se através das estratégias de promoções.

\section{Marca e as estratégias de promoção}

"Para empresas, marcas são ativos que devem gerar retorno. Já para consumidores, são elementos capazes de proporcionar felicidade, autoestima, autorrealização, segurança e diversos outros sentimentos e sensações" (Pastore, 2018 p. 17). As empresas estão investindo nas marcas para que sejam bem vistas, admiradas e desejadas, um posicionamento correto, alinhando seus valores com os propósitos de serem entendidas pelos seus consumidores. Com essas mudanças é natural assumir que as relações entre as marcas e os consumidores tenham mudado em consequência disso, passando a criar um relacionamento com as marcas que realmente gostam (Carrol \& Ahuvia, 2006; Jahn \& Kunz, 2012).

Para conquistar seus clientes as empresas precisam chamar a atenção para seus produtos posicionando sua marca de uma forma que o atraia. Os gestores de marcas deverão ter atenção as especificidades das marcas e dos indivíduos que a consomem, de modo a alcançarem vantagens competitivas sobre a concorrência (Jahn \& Kunz, 2012; Sarkar, 2011; Turgut \& Gultekin, 2015). Pois, se a empresa não disponibiliza algo de diferente, os consumidores não veem razão para não preferir pela concorrência. Um exemplo de posicionamento segundo Frankenthal (2018), tem sido a Coca-Cola é uma marca que sempre se apoiou em valores como Amizade, Felicidade, Alegria, Partilha, União e Diversão para se posicionar. A marca passa a ter uma identidade tangível que faz apelos tangíveis como toca, pegar, ouvir e observar se mover. Quando o consumidor compra um refrigerante, ele não diz que está bebendo um refrigerante ele diz que está bebendo uma Coca-Cola.

Outro atributo da marca são os símbolos, neste sentido Raithel, Taylor e Hock (2016) afirmam que o símbolo, é capaz de se impregnar de significados para serem veiculados ao consumidor e de expressar a visibilidade, que envolve atitudes, posturas, valores, fácil de lembrar, viabiliza a consciência e o reconhecimento de marca. 0 símbolo é a forma mais rápida de comunicação e a mais antiga, pois mesmo sendo analfabeto os consumidores reconhecem a marca. As cores também são ferramentas utilizadas pelas empresas na construção da marca. 0 Quadro 02 apresenta as principais cores e seus significados nas marcas mais valiosas segundo a lista da Forbes.

\begin{tabular}{|c|c|}
\hline Cor/ Empresas & Significado \\
\hline $35 \%$ usam azul. & Ela transmite confiança, responsabilidade e calma. \\
\hline $30 \%$ usam vermelho. & \\
\hline \\
\hline
\end{tabular}




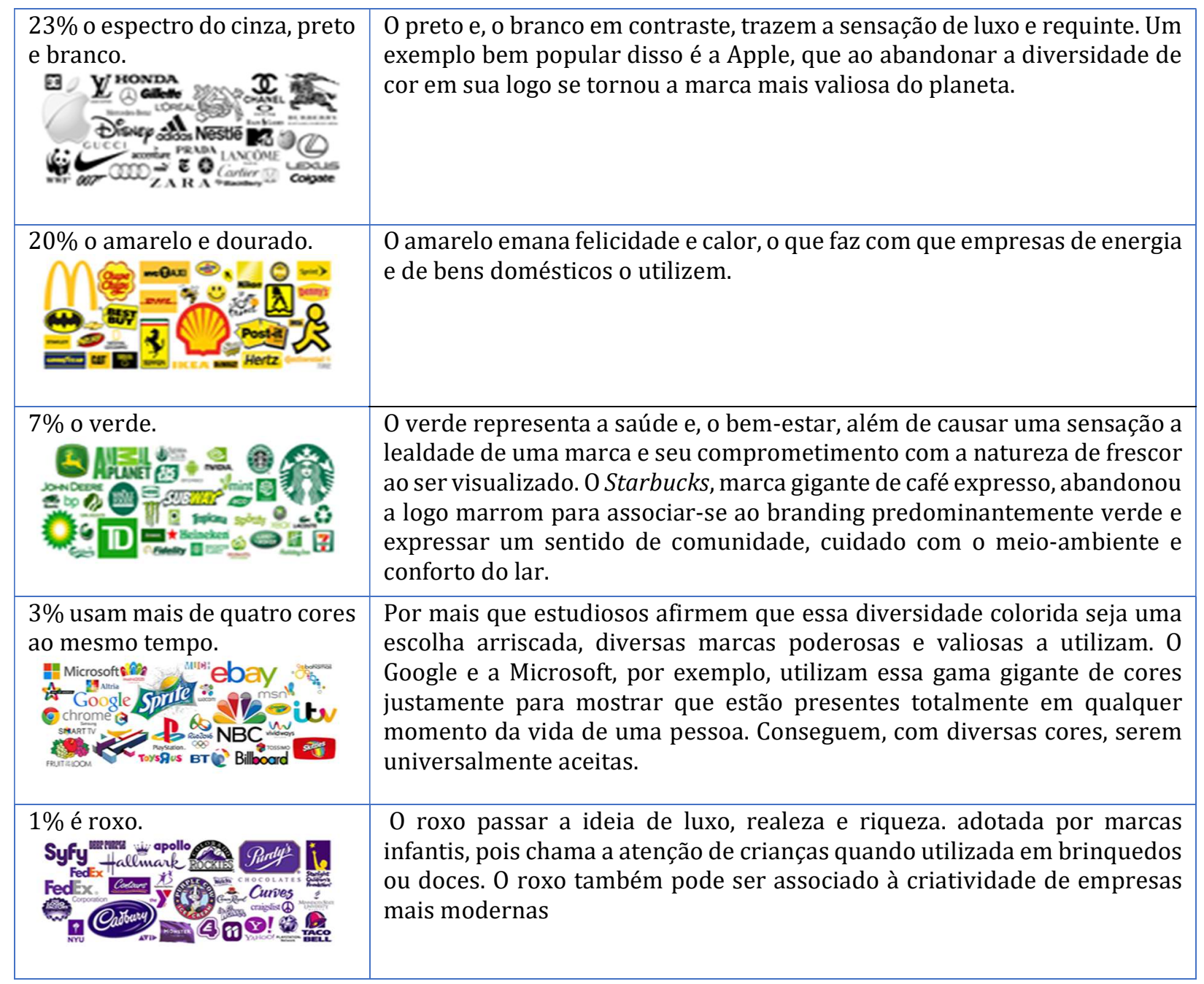

Fonte: Cardoso (2016)

Quadro 02. As principais cores e seus significados nas empresas mais valiosas

Uma forma de estratégia de promoção que está em alta é a comunicação integrada do marketing. Um anúncio de televisão já não é, na verdade, apenas um anúncio para televisão, é um conteúdo em vídeo que pode ser visto em qualquer lugar, seja no tablet, celular ou um computador (Kotler \& Armstrong, 2015). Uma nova forma de pensar a comunicação, através de mídias pagas, próprias, conquistadas e compartilhadas (Torres, 2009). A mídia paga, inclui canais promocionais pagos pelos patrocinadores e mídia tradicional.

Já a mídia própria são os canais, sites, blogs, as páginas sociais da própria empresa, enquanto a mídia conquistada utiliza os mesmos canais da mídia própria, mas não são pagos e não são controlados pela empresa. Por fim a mídia compartilhada inclui os meios que os próprios consumidores compartilham, em sites, blogs, redes sociais, canais virais além, do boca a boca.

Para chegar até a consumação da compra é necessário passar por alguns fatores em que os profissionais do marketing devem estar atentos. Um fator de grande relevância é o fator cultural, pois desde o nascimento há influência dos costumes da família, da escola que frequenta, na religião e tudo isso será determinante nas preferências e nos hábitos de consumo deste quando adulto. Os fatores sociais estão associados a status, a família, a grupo de amigos, vizinhos, colegas de trabalho que diretamente ou indiretamente influenciam as atitudes e escolhas de produtos ou marcas.

Os fatores pessoais estão relacionados com a condição econômica do consumidor, com o estilo de vida, personalidade, profissão, ocupação, idade, estado civil e estágio no ciclo da vida. Por último, os fatores psicológicos; as pessoas podem compartilhar um grupo consistente de características, imagens 
ou emoções quando eles recordam ou experimentam um determinado lugar, diante dos estímulos levará à decisão ou não da compra (Ocke, 2018).

Além dos fatores que tem relevância na hora da compra o consumidor passa por algumas fases. Engel, Blackwell e Minard (2013) fazem uma comparação com um "mapa" descrevem o processo de compra por etapas que devem ser seguidas continuamente para que todo o processo tenha sucesso. Faz parte do processo: reconhecimento da necessidade (estágio inicial do desejo), busca de informação (estágio das influências), avaliação de alternativas (critérios de avaliação e escolhas), compra (estágio de aquisição), consumo (uso dos bens ou serviços adquiridos), avaliação pós-consumo (feedbacks) e descarte.

\section{Promoção sensorial e pessoas com deficiência}

Pessoas que possuem alguma deficiência têm alguma limitação, mas não deixam de ser consumidoras e o marketing pode estar presente em suas vidas tanto quanto de alguém que não tenha de nenhuma limitação. A Convenção Sobre os Direitos das Pessoas com Deficiência da ONU (2006) conceitua a deficiência em ascenção, no Art. 1ํ da lei ํㅡ⒔146, de 6 de julho de 2015 declara:

É instituída a Lei Brasileira de Inclusão da Pessoa com Deficiência (Estatuto da Pessoa com Deficiência), destinada a assegurar e a promover, em condições de igualdade, o exercício dos direitos e das liberdades fundamentais por pessoa com deficiência, visando à sua inclusão social e cidadania (Decreto Lei ㄲo 13.146/2015, 2015 p. 1219).

Já o artigo $2^{\circ}$ desta mesma lei citada acima, traz o conceito de pessoas com deficiência,

Considera-se pessoa com deficiência aquela que tem impedimento de longo prazo de natureza física, mental, intelectual ou sensorial, o qual, em interação com uma ou mais barreiras, pode obstruir sua participação plena e efetiva na sociedade em igualdade de condições com as demais pessoas (Decreto Lei 끌 13.146/2015, 2015 p.1219).

A lei também assegura no capítulo II a partir do artigo 63 de que essas pessoas tenham acesso à informação e à comunicação como acessibilidade nos sítios da internet, tecnologias assistivas, legenda oculta, janela com intérprete da Libras, áudio descrição e muitos outros.

Outra referência no marketing de experiência é a Coca-Cola que ao longo do tempo evoluiu para atingir mais pessoas. Uma das suas propagandas sensoriais foi através do som, levando o conceito 'Abra a felicidade', a Coca-Cola decidiu abrir sorrisos dos consumidores no caixa do supermercado. Segundo Coca-Cola (2014), toda vez que a funcionária do caixa passava no leitor de códigos de barras de uma Coca-Cola, ouviu-se um "beep" diferente, e era o jingle oficial da marca. Algo que com certeza ficará na lembrança de seus consumidores sejam eles com alguma deficiência ou não, até porque seu jingle é conhecido mundialmente.

Como já foi mencionado, as pessoas com alguma deficiência são consumidoras, e devem ser inclusas na comunicação de massa e fazer parte de toda a grade de público alvo. Seguindo o que a legislação determina no artigo art. $1^{\circ}$ da lei $n^{\circ} 13.146$, algumas empresas levaram a sério a inclusão deste público que adotaram novas tecnologias como por exemplo a tecnologia assistiva. "Tecnologia Assistiva objetiva promover a funcionalidade, relacionada à atividade e participação de pessoas com deficiência, incapacidades ou mobilidade reduzida, visando sua autonomia, independência, qualidade de vida e inclusão social" (Galvão Filho \& Danascena, 2009, p. 26).

A Apple tem oferecido produtos e serviços em que todos podem usar sem nenhuma restrição de usabilidade, dentro da tecnologia assistiva um recurso chamado voiceover. No Site institucional da Apple, existe uma aba de destaque para "Acessibilidade". Nesta janela são esclarecidos os diferenciais dos aparelhos da marca para garantir que pessoas com deficiência passam utilizar os produtos sem prejuízo. No site declara que este recurso foi criado para todos, "com ele, um cego pode tirar selfies em grupo, um surdo pode ligar para a mãe em outro país e um tetraplégico pode enviar mensagens de texto para os amigos". 
O braille também considerado, tecnologia assistiva já está presente em vários produtos e embalagens para auxiliar deficientes visuais a entender o produto e identificar a marca deste. "O sistema Braille permitiu que indivíduos cegos saíssem do seu mundo específico, para compartilharem de forma mais abrangente, esferas comuns de realidade" (Belarmino, 2004, p. 5). As promoções são recursos estratégico, que ajudam a estreitar a ligação entre o produto e o consumidor, suas possibilidades prometem tornar as experiências de compra muito mais interessantes.

\section{METODOLOGIA}

Nesta seção, apresenta-se os procedimentos metodológicos utilizados para responder à problemática e aos objetivos deste estudo. A abordagem de pesquisa que melhor correspondeu aos propósitos deste trabalho é de cunho qualitativo. Quanto aos objetivos, traçou-se um plano de caráter exploratório e descritivo, quanto aos procedimentos técnicos, contempla um estudo de campo. 0 método de coleta de dados se deu por uma entrevista, semiestruturada. A análise dos dados através da análise de conteúdo.

Na pesquisa qualitativa, de acordo com Silva e Menezes (2001), há um vínculo ligando o mundo objetivo e a subjetividade do sujeito que não pode ser traduzido em números, fazendo com que a interpretação dos fenômenos e a atribuição de significados sejam as bases para a obtenção dos resultados.

A pesquisa contou com objetivos exploratórios e descritivos, isso porque propõe-se a explorar o fenômeno, perfilar novas ideias e criar soluções alternativas para o problema postos. Segundo Gonçalves (2014), a pesquisa exploratória tenciona à descoberta, o achado, a aclaração de fenômenos ou a explicação daqueles que não eram aceitos apesar de evidentes. Marconi e Lakatos (2010) explicam que esse tipo de pesquisa descritiva procura descrever as características de determinada população ou fenômeno ou o estabelecimento de relações entre variáveis.

A coleta de dados se deu a partir da pesquisa de campo. Conforme Vergara (2009), a pesquisa de campo, consiste na investigação empírica realizada no local onde ocorre ou ocorreu um fenômeno ou que dispõe de elementos para explicá-lo. Neste sentido optou-se pela entrevista semiestruturada, que contou com um roteiro de 5 (cinco) perguntas baseadas na literatura e estudos semelhantes na área, já que não foram identificados estudos abordando exatamente a mesma proposta. Para tanto, a coleta de dados incluiu entrevistas com roteiro semiestruturado, contendo perguntas relacionadas a percepção de marcas famosas, preferências por marcas e percepção da comunicação para pessoas com deficiência. Além do roteiro de entrevista foi utilizado como suporte, uma adaptação do uso das técnicas projetivas, onde são utilizadas imagens, vídeos e outros e são avaliadas reações. Badenhausen (2019), para isso foram usados rankings de marcas mais famosas no mundo (Forbes), que foram lidas (para os deficientes visuais) e mostradas (logo marca), para os deficientes auditivos, e os mesmos foram questionados se conheciam, além da observação de reações e sentimentos a respeito das marcas.

Os sujeitos que colaboram com a pesquisa foram pessoas com dois tipos de deficiências sensoriais: visuais e auditivas. A seleção aconteceu por acessibilidade, sendo pessoas do convívio da pesquisadora e indicados para a participação na pesquisa. Os participantes foram sondados previamente para esta participação e concordaram voluntariamente e no total foram 5 (cinco) respondentes, sendo 2 (dois) com deficiência visual e 3 (três) com deficiência auditiva, todos moradores de Santa Maria, com idade acima de 20 anos.

As entrevistas foram realizadas no local mais conveniente para o respondente, a ser acordado com cada um. No momento das entrevistas, mediante autorização e consentimento previsto na Resolução 510/16 os individuos serão entrevistados. Os indivíduos foram gravados com áudio e video, para captar suas reações, emoções e percepções do que estão vivenciando. Todos estes materiais juntamente com as respostas foram analisados e interpretados. Cabe ressaltar que, houve a necessidade de intérpretes já contatados que acompanharam todas as etapas da pesquisa, para auxiliar na comunicação entre os participantes.

As entrevistas foram aplicadas no mês de setembro de 2019 individualmente em suas residências, na associação de cegos e na Universidade Fransciscana. As entrevistas foram gravadas e transcritas e duraram em média 20 minutos. Neste momento a análise se deu por meio de uma 
adaptação da proposta da Bardin (2010) para análise de conteúdo. Pré-análise do material coletado que corresponde a Leitura flutuante das entrevistas, Codificação condiz a análise as temáticas (análise de temas chave e confronto com a literatura) observando as respostas e comentários realizados pelos respondentes e a categorização refere-se a análise categorial por se tratar da mais antiga técnica e que funciona através do reagrupamento do texto a partir da codificação de temáticas. A categorização oferece diferentes possibilidades de aplicação, tendo sido escolhida a investigação dos temas e/ou análise temática em função do objetivo qualitativo desta fase e não quantitativo.

A análise de conteúdo, configura-se como um conjunto de técnicas de análise das comunicações que faz uso de procedimentos sistemáticos e objetivos de descrição do conteúdo das mensagens (Bardin, 2010). Para apresentação dos resultados sobre percepções e reações diante das marcas optou-se por usar a representação de word clouds (nuvem de palavras) apresentando de maneira visual a diferença das principais questões manifestadas pelos respondentes. Além disso, foram descritos e analisados os aspectos mais relevantes. Para essa etapa da análise usou-se word clouds.

\section{ANÁLISE DOS RESULTADOS}

Os resultados contemplaram uma divisão em três categorias. Sendo a primeira categoria o Perfil dos respondentes, o consumidor com deficiência e o processo de compras, a segunda categoria a Lembrança da marca e deficiência sensorial e a terceira fidelidade, percepções e reações diante das marcas.

\section{O consumidor com deficiência e o processo de compra}

Nesta categoria foram descritos e analisados os perfis dos respondentes, bem como seu envolvimento no processo de compra como consumidores. Os respondentes foram chamados respectivamente de respondente A, B, C, D e E. A seguir no Quadro 03 apresenta a descrição do perfil dos respondentes.

\begin{tabular}{|c|c|c|c|c|c|}
\hline & $\mathbf{A}$ & B & $\mathrm{C}$ & D & $\mathbf{E}$ \\
\hline Idade & 23 & 61 & 20 & 44 & 71 \\
\hline Gênero & Feminino & Feminino & Masculino & Feminino & feminino \\
\hline Ocupação & $\begin{array}{l}\text { Estagiária na } \\
\text { área contábil }\end{array}$ & $\begin{array}{l}\text { Trabalha em } \\
\text { Empresa na } \\
\text { área da saúde }\end{array}$ & Estudante & Não trabalha & $\begin{array}{l}\text { Professora } \\
\text { Braile/vice- } \\
\text { presidente da } \\
\text { associação dos } \\
\text { cegos } \\
\text { deficientes } \\
\text { visuais. }\end{array}$ \\
\hline Formação & $\begin{array}{l}\text { Estudante de } \\
\text { ciências } \\
\text { Contábeis }\end{array}$ & Ensino Médio & $\begin{array}{ll}\text { Estudante de } \\
\text { desenho } \\
\text { industrial }\end{array}$ & 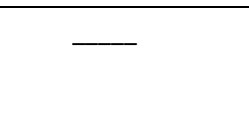 & $\begin{array}{l}\text { Professora de } \\
\text { Braile }\end{array}$ \\
\hline $\begin{array}{l}\text { Características } \\
\text { Pessoais }\end{array}$ & $\begin{array}{l}\text { Surda de } \\
\text { nascença, faz } \\
\text { leitura labial é } \\
\text { alfabetizada. Se } \\
\text { comunica } \\
\text { também por } \\
\text { línguas } \\
\text { brasileira de } \\
\text { sinais (libras) }\end{array}$ & $\begin{array}{l}\text { Surda a partir } \\
\text { dos quatro } \\
\text { anos por erro } \\
\text { de } \\
\text { medicamento, } \\
\text { alfabetizada, se } \\
\text { comunica } \\
\text { também por } \\
\text { língua } \\
\text { brasileira de } \\
\text { sinais (libras) }\end{array}$ & $\begin{array}{l}\text { Surdo de } \\
\text { nascença, se } \\
\text { comunica por } \\
\text { língua } \\
\text { brasileira de } \\
\text { sinais (libras) }\end{array}$ & $\begin{array}{l}\text { Cega aos } 24 \\
\text { anos devido a } \\
\text { uma trombose } \\
\text { no cérebro. } \\
\text { Faz leitura em } \\
\text { braile. }\end{array}$ & $\begin{array}{lr}\text { Cega } & \text { desde } \\
\text { nascença, } & \text { faz } \\
\text { leitura } & \text { em } \\
\text { braile. } & \\
& \end{array}$ \\
\hline
\end{tabular}

Fonte: elaborada pela autora

Quadro 03. Descrição do perfil dos respondentes 
Sobre o envolvimento no processo de compra pôde-se perceber que apesar das deficiências sensoriais auditivas e visuais, quase todos os respondentes envolvem-se no processo de compra de alguma forma, seja na elaboração da lista de compras ou indicação de preferências por marcas. As respondentes D e E, que são cegas realizam o levantamento de necessidades, fazem lista de compra e compram seus próprios produtos, dependendo de auxílio apenas na operacionalização da compra dentro do supermercado. De acordo com a entrevistada D "faço minhas compras e minha lista pois enxergava até aos 24 anos de idades, lembro de marcas que usava antes de ficar cega como o Leite Moça e o sabão em pó Omo", já a respondente E, que também faz sua lista e depende de ajuda apenas no supermercado menciona ainda que, possui algumas preferências por marca, no entanto nota-se certa limitação de conhecimento de produtos em função de sua fala "sempre comprei Melitta, quase nunca experimentei outro, nunca me ofereceram". Quando questionada sobre o porquê da preferência a respondente não soube explicar e deu a entender que até provaria outros, mas não conhece.

Quando uma marca permanece na memória dos clientes para Aaker e Joachimsthaler (2007) significa que foi implementada através de uma estratégia de visibilidade da marca, a qual passa estar ligada ao processo de compras. Por mais que exista uma grande gama de anúncios, propagandas para este público específico, ainda há uma deficiência de comunicação clara em relação dos produtos e marcas. Para Alves (2019) não basta olhar para fora das organizações e ver somente as necessidades dos consumidores, é preciso dialogar com eles.

Diversas dinâmicas de mudança de mercado são prováveis quando os consumidores são mais ou menos legítimos aos olhos dos profissionais de marketing convencionais e nos casos em que as mudanças que os consumidores procuram são mais ou menos consistentes com as lógicas prevalecentes (Scaraboto \& Fischer, 2013). 0 que indica que talvez, tal público, por mais que represente uma grande fatia da população, ainda não tem suas necessidades percebidas e legitimadas pela sociedade, e somente a parti disso, organizações e seus departamentos de Marketing podem voltar seus olhos para esse grupo de consumidores.

A maioria dos entrevistados relatou sobre as compras habituais na qual tem pouquíssimo envolvimento emocional. Mathias (2018) confirma que um ponto importante é tentar gerar maior envolvimento do consumidor com a marca, criando fatores emocionais que se ligam ao produto (como no caso das conhecidas propagandas de margarina, mostram o convívio com a família pela manhã).

0 respondente $\mathrm{C}$ demonstra envolvimento desde a infância, abordando inclusive a participação dos pais na sua construção como consumidor, já que lhe ensinaram a escolher e participar. Segundo o mesmo: "quando eu era pequeno a mãe me levava junto, para observar e aprender, me acostumei a ir junto, ver e observar os produtos, depois, maior a mãe fazia uma lista de compras para eu ir sozinho, minhas marcas favoritas são o salgadinho Doritos e a Coca-Cola." Portanto, à medida em que os consumidores experienciam as marcas, tendem a formar vínculos relacionais com as mesmas (Ramaseshan \& Stein, 2014). Por sua vez, estes vínculos relacionais são passíveis de motivar o consumidor a manter a relação por longo prazo, gerando a fidelidade a algumas marcas específicas.

Em contrapartida a respondente A (surda), é a única que não se envolve no processo de compra em nenhuma etapa, também menciona o papel dos pais, que fazem as escolhas dos produtos e marcas que ela consome, ao ser indagada sobre preferências pessoais e atributos de marca a mesma não demonstrou interesse ou preocupação com tais questões, deixando as decisões todas a cargo da família. A mesma afirma que apenas "costumo comprar roupa e calçado, mas não tenho preferência por marca procuro ver o que fica mais confortável". Apesar de afirmar que não se preocupa com marcas cita duas preferidas Gaston e Americanas.

Consumidores sem marcas específicas costumam experienciar nas lojas físicas, ao olhar e experimentar os produtos, se tornando clientes multimarcas, pois a experiência vai determinar a compra. Os ambientes de venda das marcas, nomeadamente as suas lojas físicas, são hoje em dia fortemente utilizados como um território privilegiado para o reforço da relação marca-consumidor, nomeadamente através da criação de experiências em loja (Bagdare, 2013).

De acordo com o que os respondentes relataram de alguma forma eles conseguem comprar. Seja pelo modo convencional que é a fala, pedindo pelo produto como também por gestos ou escrita. Conforme Solomon (2016) o processo de compra se inicia pela identificação do problema, ou seja, a necessidade de compra, que pode ter variações conforme a necessidade. A respondente D que hoje é 
cega, mas por 24 anos ter enxergado consegue recordar, lembrar de algumas marcas associando aos produtos que utilizava e que ainda utiliza. "Lembrar-se da marca de um produto significa que ela está armazenada na sua memória em uma associação com aquele produto" (Pastore , 2018, p. 117.)

Uma das respondentes deixa claro na sua fala que usa sempre a mesma marca de café porque não teve a oportunidade de escolha, sendo que existe uma diversidade de marcas e produtos. Segundo Torneiro (2019) o problema é que as pessoas podem não ser atingidas pela publicidade por causa da falta de recursos como audiodescrição, língua brasileira de sinais (libras) e legendagem descritiva. Já Cardoso, Corrêa, Peduzzi (2020) afirmam que muitas pessoas com deficiência alegam dificuldade de comparar produtos. Como estratégia, aproximam-se de produtos conhecidos. Empresas poderiam adotar estratégias diferentes, buscando realmente atingir esse consumidor, tais como inserir o Braille na embalagem, realizar testes com consumidores com baixa visão ou audição; estipular tamanhos mínimos de fonte e valores mínimos de contraste para rótulos de embalagens.

\section{Lembrança da marca e deficiência sensorial}

Nesta categoria foram analisados a lembrança, atratividade das marcas e percepção de embalagens, volume de produtos e linguagens para suas limitações. Em relação as lembranças de marcas foram questionadas a cada respondente se lembram de marcas que se preocupam com as deficiências sensoriais. Dos cinco respondentes apenas dois tem essa lembrança os respondentes C e E.

0 respondente $\mathrm{C}$, surdo afirma que sua percepção é totalmente visual, como possui o hábito de assistir televisão, acesso as redes sociais e internet, passa a conhecer as marcas seus produtos através de propagandas. Afirma: "vejo na tv, propagandas, internet, e compartilham nas redes sociais me chama atenção eu vou e experimento." O posicionamento das marcas faz toda a diferença para esses consumidores. Conforme, Kotler e Keller (2013, p. 179) "a implementação do posicionamento da marca requer que os consumidores entendam o que marca oferece e o que faz dela uma escolha competitiva superior". Assim como propaganda é comunicação não pessoal, paga, com patrocinador identificado visando criar e manter relacionamentos, útil para alcançar vastos públicos (Strauss \& Frost, 2006)

Assim como a respondente E Cega, que percebe as marcas pelo braile que estão inseridas em algumas embalagens. A respondente ressalta que facilitou bastante a identificação dos produtos citando a Sadia e a Natura como exemplo. Mas que infelizmente, "já estava habituada a não ter produtos que facilite a identificação". A escolha de marcas de acordo com a preocupação de acessibilidade indica que a consumidora se sente representada e respeitada por essa marca (Cardoso, Corrêa \& Peduzzi, 2020).

Os respondentes A, B e D não tiveram nenhuma lembrança de marca e nem produtos específicos que facilitasse a identificação. As respondentes A e B surdas, conseguem identificar os produtos porque são alfabetizadas tendo a facilidade em ler do que se trata os produtos. A respondentes A ainda faz leitura labial que ajuda e muito na identificação quando precisa pedir ajuda para alguém a auxiliar. A facilidade que essas respondentes têm partiu dos pais das mesmas que desde pequena frequentavam regularmente fonoaudiólogas e escolas. A respondente B não se preocupa com a marcas não tem nenhuma percepção de alguma que facilite sua identificação. Quando vai comprar as marcas ficam invisíveis olha somente os preços ressalta a respondente, "consigo ver o que está com o preço mais baixo ou mais alto".

No caso do consumidor surdo é necessário apresentar os produtos visualmente, com informações visíveis, que possam ser tocadas e sentidas de todas as maneiras, para um real conhecimento do produto antes de ser adquirido. Assim também poderá visualizar as marcas e passar a ter preferencias pela qualidade do produto. "Oferecer ao consumidor informações e incentivos e que convença o consumidor a adquirir aquele produto ou os serviços de determinada empresa e ao mesmo tempo, que gere iniciativas para as empresas conhecerem seu público" (Limeira, 2010, p. 272.).

A respondente D cega, não tem lembrança de nenhuma marca e nem percebe em produtos. Em propagandas precisa de uma descrição do que se passa, porque muitas vezes é só a música e imagem sem a fala das pessoas. A respondente conhece muitas marcas e produtos, pois ficou cega aos 24 anos, mas relatou que produtos e marcas lançados depois que ficou cega não consegue identificar com facilidade. Afirma a respondente "prefiro escutar rádio a assistir televisão". 0 comércio e o setor de 
serviços ainda estão despreparados para a inclusão desses consumidores, a maioria das marcas brasileiras, ainda ignoram a população cega como público consumidor (Pereira, 2018).

Dentro desta análise também foi questionado se houvesse uma promoção e/ou propagandas orientadas para a limitação de cada respondente isso seria mais atrativo. Os respondentes, A, B, C, D e E foram unanimes respondendo que sim, seria mais atrativo para eles. $O$ respondente $C$ surdo, complementou dizendo "procuro lugares com intérprete, no Shopping Praça Nova tem um restaurante que tem e o Mcdonalds tem um avatar que me ajuda na comunicação. A respondente B surda, enfatiza "eu poderia comprar os produtos com mais qualidade e não só pelo preço." Nesse sentido, Damascena e Farias (2013), considera que no Brasil ainda existe uma distância do alcance das leis em oferecer condições mínimas de consumo para esse público deficiente, não havendo condições ideais para as práticas de consumo. Na cultura já existe ambientes preparados para pessoas que não ouve e não vê, cinemas com legenda descritiva e legenda em libras (Gonçalves, 2019).

Quando um grupo de consumidores não se vê representado e não pode acessar grande parte da publicidade como comerciais com trilha sonora; logotipos minúsculos, sem slogans visíveis ou falados, entre outras barreiras, sua memória tenderá a buscar por empresas que minimamente buscaram se conectar, mesmo que de forma pouco planejada. Cardoso, Corrêa e Peduzzi (2020) sugerem o uso de roteiros pensados de forma multissensorial, com abordagens diferentes para que a mesma campanha possa ser usado em diferentes meios de comunicação (por exemplo, rádio e televisão) e ainda estimulando diferentes sentidos, de acordo com as possibilidades.

Dentro desta perspectiva de atratividade foi questionado aos respondentes se fossem fiéis a uma marca, se trocariam essa marca por outra com a qual tivesse facilidade na identificação e comunicação. Os respondentes A, B, C, D e E disseram que trocariam com certeza. O respondente B surdo, deixou claro que gosta muito do "X do Gulosão", indagado se trocaria essa marca e alimento que tanto gosta por outro onde tivesse facilidade de identificar e se comunicar na hora da compra e o mesmo afirma que "sim trocaria". Assim como a respondente D cega, trocaria, mas se tivesse o braile no caso de produto que tivesse mais informação. É difícil fidelizar um cliente quando ele sente que simplesmente não está recebendo o bem ou serviço que espera ou acredita que merece (Klein, 2012).

Enquanto para uns a compra vem de uma boa oferta, outros se encantam com um serviço personalizado e adaptado. Uma adaptação bem-vinda está nas roupas para pessoas cegas, a percepção do avesso das etiquetas em alto relevo. 0 desenvolvimento dos vestuários adaptados para os invisuais apresenta funcionalidade como impressões em alto relevo, facilitando a vestimenta de tais peças (Oliveira et al., 2015).

A respeito da percepção sobre a comunicação sensorial por meio de embalagens, volume de produtos e linguagens para pessoas que possuem limitações, os respondentes $A, C, D$ e E não tem percebem preocupação das empresas e marcas com isso. Enquanto a respondente B surda, ficou na dúvida se percebe, mas disse que consegue visualizar o produto que precisa quando vai comprar. A respondente A surda e E cega relataram da seguinte forma "nunca percebi". 0 respondente $C$ surdo, disse que nas lojas nunca viu, mas que um amigo disse que na loja Marisa tem uma pessoa que se comunica em libras auxiliando na compra. Já a respondente D cega também nunca percebeu e por saber que não tem nada adaptado para ela explica desta forma "eu não me aproximo e nem toco em nada, para evitar incômodos".

O estudo de Cardoso, Corrêa e Peduzzi (2020) apontam que as situações de consumo muitas vezes são complexas para pessoas com deficiência visual devido à falta de acessibilidade em produtos e serviços, dificultando a relação do público com as marcas, seja em embalagens, websites, comerciais, redes sociais ou outros pontos de contato.

Cada pessoa percebe o ambiente ao seu redor de maneira diferente, portanto é necessário entender a percepção dos consumidores e avaliar como este distingue produtos e serviços que o levam à compra (Blessa, 2011). Para as pessoas surdas, ou deficientes auditivas a sua percepção está ligado no visual, conforme Ditoiu e Caruntu, (2013) explicam que, um produto com uma aparência atraente tende a capturar com facilidade o interesse do consumidor e a prender a sua atenção por mais tempo.

Ainda existem ambientes e pessoas despreparados para atender pessoas deficientes, sejam elas sensoriais ou, não. Um atendimento de qualidade tem como objetivo principal atender as necessidades dos clientes, porém, isso é uma mudança cultural, que exige tempo e a integração e todos os envolvidos 
(Portela, Schumacher \& Borth 2013). Mas em contra partida já existe uma mobilização para atrair esse publico para dentro das lojas, através do marketing sensorial. Para Ximenez (2019), é preciso envolver o cliente, integrar produto e espaço e trazer o consumidor para dentro da loja, ele pode ser atraído pela visão de vitrines chamativas, pelo som e até pelo cheiro, por exemplo.

\section{Percepções e reações as marcas}

Nesta categoria foram analisadas as percepções em relação as marcas. Os respondentes A, B e C disseram que quando experimentam e gostam costumam comprar sempre o mesmo produto. Já o respondente é D é fiel pela qualidade do produto. A respondente E compra algumas coisas é mais ou menos fiel.

A respondente A surda, como já foi relatado anteriormente não se preocupa com marcas, mas quando se trata de perfume compra sempre o mesmo. 0 perfume que ela usa foi indicação de uma vendedora da loja do o Boticário, depois que sentiu o cheiro suave passou a comprar sempre o mesmo. Da mesma forma a respondente B surda, não costuma ser fiel a marcas. Ela também é fiel pelo olfato, pois ganhou um perfume de presente e passou a usar e comprar o mesmo. A respondente afirma "gostei do perfume que ganhei de presente".

$O$ respondente $C$ surdo, mencionou várias vezes ser fiel ao salgadinho Doritos que ama comer. É fiel a marca pelo sabor, pois provou e gostou do gosto forte, do apimentado do salgadinho. Disse que "gosto muito porque tem uma diversidade de sabores", ainda comentou que viu as propagandas do salgadinho na televisão e achou legal e decidiu experimentar e amou. Para Filser (2003) o marketing sensorial é como um conjunto de estímulos (elementos) apto para formar uma atmosfera multissensorial que acate os propósitos da marca, seja na esfera de venda, nas ações de comunicação publicitária e nas características do produto. Reis (2012), "quanto maior a estimulação dos sentidos dos potenciais consumidores, no processo de experimentação dos produtos, maior a resposta das compras.

Em contrapartida a respondente D cega, sua fidelidade se dá pela qualidade do produto. Complementa dizendo "não adianta comprar um produto barato e se decepcionar depois." E por fim a respondente $\mathrm{E}$ cega, compra vários tipos de produtos dá preferência para aqueles que tem descrição em braile, acaba preferindo esse pela facilidade de identificação. Mas diz não ser totalmente fiel citou um produto que não tem braile que costuma comprar pelo perfume que é o sabonete palmolive. A existência de escrita braile nas embalagens dos produtos reduz a necessidade de o consumidor recorrer a outrem, dando mais autonomia as pessoas cegas na hora da compra (Damascena 2013). Os consumidores experienciam as marcas, tendem a formar atitudes favoráveis e a conectar-se tornando-se fiel a marca pela qualidade que observam nos produtos (Ramaseshan \& Stein, 2014).

Foi apresentado aos respondentes algumas marcas conhecidas mundialmente Para que analisassem no momento que vissem e escutassem o nome da marca, qual sua percepção em relação as mesmas. A seguir foram criadas duas figuras que refletem por meio de nuvem de palavras, a Figura 01 as principais percepções sobre as marcas e na sequência, Figura 02 as principais reações:

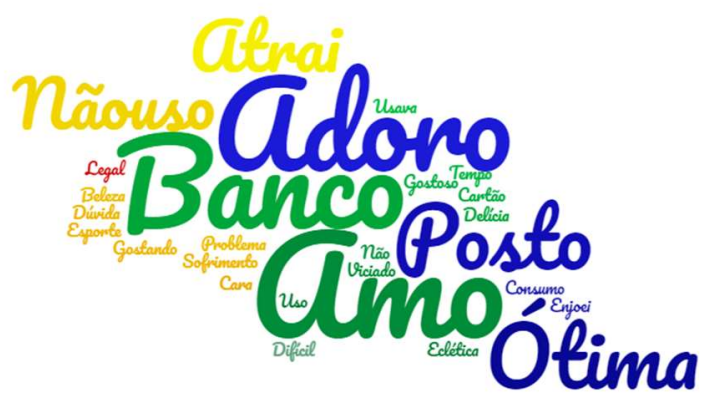

Fonte: elaborada pela autora

Figura 1. Percepções sobre as marcas

Quando apresentada aos respondentes as marcas, sendo que aos respondentes surdos eles visualizaram as marcas e aos respondentes cegos foi falado, ou seja, lido o nome da marca as respondentes. Pode -se observar que nas palavras em destaque na nuvem foram "amo" o amo referente 
a marca da Coca-Cola, em relação a palavra "Adoro" referente a marca Mcdonalds. A palavra "Ótimo" para a marca Google. Duas palavras que também estão em destaque são as palavras "Banco e Posto". Estas duas palavras os respondentes apenas repetiram quando viram ou ouviram a marca, por exemplo Banco do Brasil repetiram "banco", como algo indiferente, apenas um banco sem relevância nenhuma na vida deles, e isso aconteceu da mesma forma quando viram a marca do posto de combustível. A seguir a Figura 02 a nuvem de palavras referente as reações as marcas apresentadas.

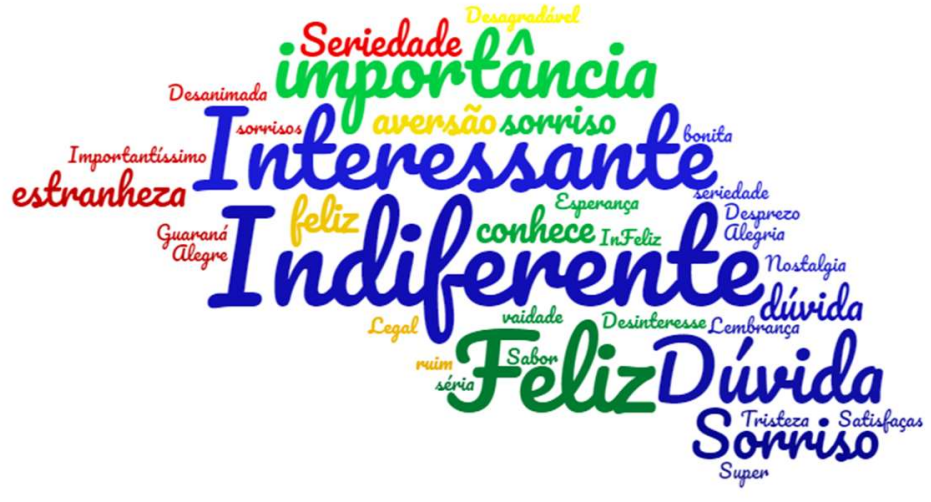

Fonte: Elaborada pela autora

Figura 2. Reações as marcas apresentadas

A figura 02 demonstra que as palavras com o tamanho maior foram as que mais se repetiram nas falas dos respondentes da pesquisa, as seguintes, Interessante, Indiferente e Feliz. Segundo Ferreira (2019) a palavra interessante significa, importante; merecedor de atenção; que provoca interesse; que não é entediante nem monótono. A palavra interessante foi uma das mais repetidas, foi direcionada a várias marcas como por exemplo Coca-Cola, Instagram e lojas Americanas entre outras. O que demonstra interesse por parte dos respondentes da pesquisa. Esse adjetivo se dá a identidade visual que conseguiu comunicar ao público os valores e o posicionamento das marcas no mercado, alguns desses elementos de marca são: nome, logotipo, embalagens de produtos e muito mais (Ramos, 2019).

Segundo Ferreira (2019) palavra indiferente significa, que não possui importância; que demonstra pouco ou nenhum interesse em relação a algo; quem nada comove; que não se importa. A palavra indiferente também foi citada várias vezes quando foi apresentada algumas marcas como, Petrobras, CVC, Bradesco, Banco do Brasil posto Ipiranga, Magazine Luiza entre outras. Se alguém está indiferente, basta uma experiência negativa para que fique insatisfeito. Por outro lado, uma experiência positiva diferenciada pode transformá-lo em um verdadeiro fã e defensor da marca. 0 que pode mudar essa situação é atendimento ao cliente, a divulgação e acessibilidade ao produto. Segundo Souki (2006, p. 30-34) "o cliente associa a marca à dor ou ao prazer, ou seja, se uma experiência lhe trouxer insatisfação, ele associará a empresa/marca e se for de prazer novamente recorrerá àquela marca/empresa". Por outro lado, a indiferença se dá pela marca ou produto não ter despertado interesse ao consumidor. Kotler \& Keller (2012, p. 144) afirmam

[...] as empresas buscam o lucro, o cliente busca o melhor custo $\mathrm{x}$ benefício, pois, os consumidores pressupõem o que querem, mas em alguns casos eles têm preferências indefinidas, ambíguas ou conflitantes e, para auxiliá-los, os colaboradores da empresa e as empresas precisam trabalhar em parceria para entender e atender suas necessidades.

Segundo Ferreira (2018) a palavra Feliz significa, que está muito contente; que se sente afortunado; que está muito satisfeito, que teve os seus desejos concretizados; contente; que obteve um resultado favorável; vantajoso; que expressa alegria. Algumas marcas ao serem vista pelos respondentes deixaram-nos feliz como por exemplo, Coca-Cola, Instagram, Face Book, Skol entre outras. Para um consumidor ou cliente ter um sentimento de felicidade significa que está satisfeito com o produto e com a marca que conseguiu atender as expectativas do cliente. Na sua forma mais básica, a 
satisfação do cliente mede como o seu produto, serviço e experiência geral fica aquém, atende ou excede às expectativas do cliente (Teixeira, 2018).

\section{CONCLUSÃO E APRECIAÇÃO CRÍTICA}

Ao analisar como as estratégias de marketing sensorial e comunicação da marca são percebidas por consumidores com deficiência pode-se afirmar que os objetivos deste trabalho foram atingidos. 0 marketing sensorial é uma tendência cada vez maior nas escolhar de empresas que buscam se diferenciar e desenvolver um posicionamento marcante. No entanto, para que uma organização possa explorar as estratégias e ações de comunicação sensorial é essencial compreender seus públicos, a participação dos sentidos para este público e como seu uso melhorar a experiência do consumidor com a Marca.

Como principal conclusão identificou-se que na percepção dos respondentes da pesquisa as marcas não buscam se conectar, despertar atenção ou dialogar por meio de estratégias multissensoriais, o que fica claro em diversos momentos ao longo da apresentação dos resultados, quando muitas vezes a escolha se devia a percepções de terceiros, que podiam perceber todos os sentidos e orientar os cegos e surdos.

Percebe-se que o público com deficiência sensorial acaba sendo desconsiderado no roll das estratégias e em suas necessidades. A comunicação da marca com acessibilidade é quase inexistente para os deficientes sensoriais, o que salienta o papel da família para estimular e ensinar desde criança, mesmo que em muitos momentos não possam fazer escolhas e avaliar diferenças, optando pelo que já é conhecido, o que quase exclui estas pessoas do processo de consumo, que hoje orienta nossa sociedade.

A alfabetização diferenciada, a leitura labial e o incentivo da família, ensina e torna o deficiente independente para realizar as compras sozinho, mas quando a questão é perceber diferenças entre produtos e marcas, os aspectos sensoriais não são explorados a ponto de promover uma identificação com estes consumidores. Em outros casos, quando a limitação sensorial chega no decorrer da vida, o consumidor mantém lembranças e ligação com aspectos afetivos, mesmo assim, nota-se que a partir da falta de visão ou audição, a possibilidade de experimentação de novas marcas se reduz ou se limita a escolhas de outras pessoas.

Verificou-se ainda que as marcas que mais investem em marketing sensorial e acessibilidade foram as que tiveram um maior impacto nos respondentes. 0 impacto se deu por declararem que as marcas são ótimas, interessantes por se sentirem feliz com os produtos, como a Coca-Cola e Mcdonalds. Consequentemente as marcas que não têm esse diferencial são as que se tornaram indiferente para os respondentes, mesmo sendo mundial ou nacionalmente conhecidas.

Em relação a lembrança da marca que se preocupam com as deficiências sensoriais, a maioria dos respondentes não lembraram. Apenas dois respondentes se manifestaram um cego e um surdo sendo com duas respostas diferentes, mas que se complementam. Por intermédio da acessibilidade e o marketing sensorial. A lembrança da respondente cega é totalmente pela acessibilidade através do braile, que não deixa de ser sensorial pois a leitura do braile é pelo toque e o surdo através do marketing sensorial em que as embalagens coloridas e o paladar foram decisivos para que lembrasse do produto e da marca.

Por fim a percepção das estratégias de campanhas de promoção voltadas ao marketing sensorial para pessoas com deficiência, nota-se que para quatro dos cinco respondente não existem campanhas epecificas, com apelo sensorial voltadas para o público com algum tipo de limitação, por mais que os respondentes sejam alfabetizados, os recursos tanto na televisão como nos computadores são pouco úteis, e para os cegos não tem audiodescrição, porque a maioria das campanhas são visuais. Nem mesmo lojas físicas estão preparadas ou utilizam aspectos táteis, olfativos ou outros para criar identificação.

Mediante ao exposto os deficientes sensoriais conseguem comprar, pois faz parte da necessidade de cada um, todos precisam consumir. Mas são limitados nas escolhas, por falta de acessibilidade e comunicação das marcas mesmo por intermédio do marketing sensorial, não consegue comunicar-se completamente com este público. Como consequência os respondentes são influenciados pelas preferencias de outras pessoas, sendo que uma das coisas que diferem as pessoas são suas preferências 
e seus gostos. Tanto que a fidelidade a algum produto se deu pela influência de terceiros e não por uma atitude espontânea dos respondentes.

Cabe portanto a reflexão para o Marketing como um todo, no sentido de ampliar seu escopo, já que além de representatividade numérica, estes consumidores possuem identidade social e individual e precisam ser atendidos. Além disso, o Marketing se mostra parcial e falho quando não percebe as possibilidade de criar experiências, conquistar afetos e criar relacionamentos ao explorar aspectos sensoriais. Como limitações acredita-se que a principal foi o fato de construir algo inovador, sem referências anteriores com o mesmo público para tal tema. Sugere-se o aprofundamento dos estudos que não tenham apenas o viés da inclusão.

\section{References}

Aaker, David A.; Joachimsthaler, Erich. (2007). Como construir marcas líderes. Porto Alegre: Bookman. Acevedo, C. R., \& Fairbanks, V. S. L. (2018). Os Efeitos do Marketing Sensorial Sobre a Experiência de Compra do Consumidor no Ponto de Venda. Revista Interdisciplinar de Marketing, 8(1), 51-67.

Alves, E. B. (2019). Consumo e sociedade: um olhar para a comunicação e suas práticas de consumo. Curitiba. Inter Saberes.

Bagdare, S. (2013). Antecedents of Retail Customer Experience. Journal of Marketing \& Communication, $8(3), 45-51$.

Badenhausen, K. (2019). As 100 marcas mais valiosas do mundo em 2019. Recuperado de https://forbes.com.br/

Bardin, L. (2010) Análise de conteúdo (4a ed.) Lisboa, Edições 70.

Benjamin, S., Bottone, E., \& Lee, M. (2020). Beyond accessibility: exploring the representation of people with disabilities in tourism promotional materials, Journal of Sustainable Tourism, 29(2-3), 295313. http://doi.org/10.1080/09669582.2020.1755295

Belarmino, J. (2004). Aspectos comunicativos da percepção tátil: a escrita em relevo como mecanismo semiótico da cultura. (2004). Tese (Doutorado em Comunicação e Semiótica da Pontifícia). Universidade Católica de São Paulo, São Paulo.

Blessa, R. (2011). Merchandising no ponto-de-venda. 4. ed. São Paulo: Atlas.

Bragança F. F.C., Zaccaria R. B., Giuliani A. C., \& Pitomba T. C. (2016). Marketing, criatividade e inovação em unidades de informação. Revista Brasileira de Marketing - ReMark, 15(2). http://doi.org/10.5585/remark.v15i2.3277

Cardoso, J. (2016). A influência das cores nas marcas. Recuperado em 13 de novembro 2019 de https://blog.welancer.com/

Cardoso, E., Corrêa, Y., \& Peduzzi R. (2020). Strategic approaches of brands to visually impaired people: Accessible communication guidelines. e-Revista LOGO, 9(1), 2020 - ISSN 2238-2542. http://doi.org/10.26771/e-Revista.LOGO/2020.1.03.

Carroll, B. A., \& Ahuvia, A. C. (2006). Some antecedents and outcomes of brand love. Marketing Letters, $17(2), 79-89$.

Damascena, E., \& Farias, S. (2013). Os elementos sensoriais em supermercados: um estudo junto a pessoas com deficiência visual na perspectiva da pesquisa transformativa do consumidor (Tese Dissertação). Universidde Federal do Pernambuco, Recife.

Decreto Lei ํㅡ 13.146/2015. (2015). Lei Brasileira de Inclusão da Pessoa com Deficiência. Estátuto da Pessoa com Deficiência, p. 1219.

Diniz, D., Barbosa, L., \& Santos, W. R. (2009, Dezembro). Deficiência, Direitos Humanos e Justiça. Sur, Rev. int. direitos humanos. 6(11). https://doi.org/10.1590/S1806-64452009000200004

Ditoiu, M., \& Caruntu, A. (2013, Janeiro). Sensory experiences regarding five-dimensional brand destination. Procedia: Social and Behavioral Sciences, 109(1), 301-306. http://doi.org/10.1016/j.sbspro.2013.12.461

Engel, J. F., Blackwell, R. D., \& Miniard, P. W. (2013). Comportamento do Consumidor. 1. ed. São Paulo: Cengage Learning. 
Ferreira, A. B. de H. (2019). Dicionário Online de Português. Recuperado em 21 de novembro 2019 de https://www.dicio.com.br/

Filser, M. (2003, Setembro). Le marketing sensoriel: la quête de l'intégration théorique et managériale. Revue Française du Marketing, 4/5(194), 5-11.

Frankenthal, R. (2018). Posicionamento de marca. Recuperado em 12 de novembro 2019 de https://mindminers.com

Galvão, F., T. A. et al. (2009). Conceituação e estudo de normas. In: Brasil, Tecnologia Assistiva. Brasília: CAT/SEDH/PR, 13-39. Recuperado de https://www.docsity.com/pt/livro-tecnologiaassistiva/4813463/

Gonçalves, C. (2019). O que Santa Maria oferece de cultura para quem não ouve e quem não vê. Recuperado em 18 de novembro de 2019 de www.diariosm.com.br

Gonçalves, H. A. (2014). Manual de metodologia da pesquisa científica. 2 ed. São Paulo: Avercamp.

Holbrook, M. B., \& Hirschman, E. C. (1982, Setembro) The Experiential aspects of consumption: consumer fantasies, feelings, and fun. Journal of Consumer Research, 9(2), 132-140, 1982. https://doi.org/10.1086/208906

Instituto Brasileiro Geografia e Estatisco (IBGE). (2010). Censo Demográfico. Recuperado em 9 de abril 2019 de https://www.ibge.gov.br

Jahn, B., \& Kunz, W. (2012, Junho). How to transform consumers into fans of your brand. Journal of Service Management, 23(3), 344-361. http://doi.org/10.1108/09564231211248444

Jiménez M., G., \& Zambrano, E. (2018, Novembro). Marketing Sensorial: merchandising por meio das emoções no ponto de venda. Análise de um caso. AdComunica: revista cientifica de estratégica, tendências e inovação em comunicação. 15, 235-253. http://dx.doi.org/10.6035/21740992.2018.15.12

Klein, E. (2012). Como ser fiel ao que o cliente espera da sua marca? Recuperado em 19 de novembro 2019 de https://administradores.com.br

Kotler, P., \& Armstrong, G. (2015). Princípios de Marketing. 15. ed. São Paulo: Pearson Prentice Hall.

Kotler, P., \& Keller, K. L. (2012). Administração de Marketing. 14. ed. São Paulo, Pearson Education do Brasil.

Kotler, P., \& Keller, K. L. (2013). Marketing essencial: conceitos, estratégias e casos. 5ạ.ed. São Paulo: Pearson.

Kotler P., Setiawan I., \& Kartajaya H. (2017). Marketing 4.0: Mudança do tradicional para o digital. Coimbra: Actual.

Krishna, A. (2011). An integrative review of sensory marketing: Engaging the senses to affect perception, judgment and behavior. Journal of Consumer Psychology, v. 22, n. 3, p. 332-351. https://doi.org/10.1016/i.jcps.2011.08.003

Limeira, T. M. V. (2010). Administração das Comunicações de Marketing, São Paulo: Saraiva.

Lindstrom, M. (2012). Brand sense: Segredos sensoriais por trás das coisas que compramos. Porto Alegre: Bookman.

Marconi, M. de A., \& Lakatos, E. M. (2010). Fundamentos de metodologia científica. 7. ed. São Paulo: Atlas.

Mathias, L. (2018). A influência dos tipos de comportamento na tomada de decisão do consumidor. Recuperado em 18 de novembro $2019 \mathrm{de}$ https://mindminers.com

Minuzzi, G., \& Larentis F. (2014, Setembro/Dezembro) Marketing: definições, aplicações, tendências e desafios do profissional. Revista de Administração IMED, 4(1), 80-97.

Miethlich, B., \& Oldenburg, A. (2019). How Social Inclusion Promotes Sales: An Analysis of the Example of Employing People with Disabilities, Journal of Marketing Research and Case Studies, 463316, DOI: $10.5171 / 2019.463316$

Oliveira, D. V., Faganelo L. R., Rossi A., Orsi M.\& Paschoarelli L. C. (2015, Outubro). Aspectos Inclusivos da Moda com Foco nas Pessoas com Deficiência Visual. Moda Palavra E-periódico, Florianópolis, $1(9), 116-139$.

Ocke, M. A. M. O. (2018). Produto Ampliado dos lugares: Uma Perspectivq de Marketing. Revista Interdisciplinar de Marketing, 7(2), 139-155, 2018.

Parente, J. (2010). Varejo no Brasil. São Paulo: Atlas.

Pastore, C. M. A. (2018). Gestão da marca. Cutritiba. Inter Saberes. 
Pereira, M. E. (2018). Deficientes visuais cobram melhorias no atendimento do comércio e de serviços. Recuperado em 18 de novembro de 2018 de https://www.em.com.br/

Portela, K. C. A., Schumacher, A. J., \& Borth, M. R. (2013). Ferramentas do Secretário Executivo. 2.ed. Cuiabá/MT: Dos Autores.

Raithel, S., Taylor, C., \& Hock, S. (2016). Are Super Bowl ads a super waste of money? Examining the intermediary roles of customer-based brand equity and customer equity effects. Journal of Business Research, 69(9).

Ramaseshan, B. \& Stein, A. (2014). Connecting the dots between brand experience and brand loyalty: The mediating role of brand personality and brand relationships. Journal of Brand Management, 1(21), 664-683. Recuperado de https://link.springer.com/article/10.1057/bm.2014.23

Ramos, A. J. (2019). Entenda o que é identidade visual e qual a sua importância para a estratégia do seu negócio. Recuperado em 19 de novembro de 2019 de https://rockcontent.com/

Reis, Artur. (2012). Marketing Olfativo - Conquistando os Consumidores pelo Cheiro. Recuperado em 18 de novembro 2019 de https://professorarturreis.blogspot.com/2012/09/marketing-olfativoconquistando-os.html/

Rez, R. (2018). Marketing 4.0: do Tradicional ao Digital, passo a passo. Recuperado em 11 de novembro de 2019 de https://novaescolademarketing.com.br/

Silva, E. L.; Menezes, E. M. (2001). Metodologia da pesquisa e elaboração de dissertação. Florianópolis: Laboratório de Ensino à Distância da UFSC. Recuperado de http://cursos.unipampa.edu.br/cursos/ppgcb/files/2011/03/Metodologia-da-Pesquisa-3aedicao.pdf

Site Institucional da Apple. (2019). Acessibilidade. Recuperado em 05 de maio de 2019 de https://www.apple.com/br/acessibility/iphone

Site Wordcloud. Gerador de Wordcloud online gratuito. Recuperado em 25 de novembro de 2019 de www.wordcloud.com

Sarkar, A. (2011). Romancing with A Brand: A Conceptual Analysis of Romantic Consumer-Brand Relationship. Management \& Marketing, 6(1).

Soares, M. M. (2013). Implementação da Estratégia de Marketing Sensorial: uma abordagem empírica. Dissertação (Mestrado em Ciências Econômicas e Empresariais). Universidade dos Açores. Portugal.

Solomon, M. R. (2016). o comportamento do consumidor: comprando, possuindo e sendo. 11. Ed. Porto Alegre: Book man.

Souki, Ô. (2006). As 7 Chaves da Fidelização de Clientes. Harbra, São Paulo.

Scaraboto, D., \& Fischer, E. (2013). Frustrated fatshionistas: An institutional theory perspective on consumer quests for greater choice in mainstream markets. Journal of Consumer Research, 39(6), 1234-1257.

Strauss, J., \& Frost, R. D. E. (2001). Marketing. Englewood Cliffs. Nj Prentice hall. São Paulo.

Teixeira, R. F. (2018). Satisfação do Cliente: tudo o que você precisa saber. Recuperado em 21 de novembro de 2019 de https://blog.deskmanager.com.br/

Torneiro, Gustavo. (2019). O poder de compra das pessoas com deficiência. Recuperado em 25 de novembro 2019 de https://sondery.com.br

Torres, C. (2009). A bíblia do marketing digital. São Paulo: Novatec.

Turgut, M. U., \& Gultekin, B. (2015). The Critical Role of Brand Love in Clothing Brands. Journal of Business Economics and Finance, 4(1), 126-152.

Vergara, S. C. (2009). Projetos e Relatórios de Pesquisa em Administração. 11a ed. São Paulo: Atlas.

Video. (2014). Marketing de Experiência - Case Coca-Cola. Recuperado em 03 de maio de 2019 de www.youtube.com/watch?v=63TfggFOubI

Ximenez, A. (2019). Marketing sensorial: mexa com as emoções dos seus clientes. Recuperado em 19 de novembro de 2019 de https://mutantbr.com/ 